\title{
Associations of Optical Coherence Tomography Parameters and Pathological Process in Multiple Sclerosis: Evidence from a Systematic Review and Meta-Analysis
}

\author{
Eleni Mitona ${ }^{1}$, Sygkliti-Henrietta Pelidou ${ }^{2,4^{*}}$, Evangelia Ntzani ${ }^{3}$, Christos Bakirtzis ${ }^{4}$, Marina Boziki ${ }^{4}$, Ioannis \\ Nikolaidis ${ }^{4}$, Christos Kalogeropoulos ${ }^{1}$ and Ioannis Asproudis ${ }^{1}$
}

${ }^{1}$ Department of Ophthalmology, University of Ioannina, Greece

${ }^{2}$ Department of Neurology, Division of Health Sciences, University of Ioannina, Greece

${ }^{3}$ Department of Epidemiology, Division of Health Sciences, University of Ioannina, Greece

${ }^{4}$ Department of Neurology, Aristotle University of Thessaloniki, Greece

Submission: July 15, 2019; Published: August 23, 2019

*Corresponding author: Sygkliti-Henrietta Pelidou, Department of Neurology, University of Ioannina, University Campus, Division of Health Sciences, Medical School, Ioannina, Greece

Abstract

Introduction: The usefulness of Optical Coherence Tomography (OCT) in accessing axonal loss and visual pathway involvement in the pathological process of Multiple Sclerosis (MS) is increasingly accepted the last ten years. The present meta-analysis aimed to explore the current evidence regarding potential associations between OCT parameters and pathological process of MS.

Methods: A thorough systematic search and critical appraisal of existing medical literature was done using OCT to screen patients with MS. Pubmed/Medline databases were searched from 2006 to the end of February 2019 using the terms Optic Neuritis (ON), OCT, Retinal Nerve Fiber Layer (RNFL), and MS. The obtained data were analyzed by Cochrane Collaborations Review Manager 5.3.

Results: The identified 65 studies examined OCT parameters in patients with MS and healthy subjects. The estimated RNFL loss in MS patients with non-ON compared to controls was lower than the one following MSON. Greater retinal thinning was observed in patients' eyes with prior history of $\mathrm{ON}$ than in those of controls. Moreover, visual acuity measurements were found to be strongly in consistent with the RNFL thickness values.

Conclusion: RNFL and Macular Volume (MV) measurements might be able to reveal information concerning the visual pathway axonal loss and neuronal cell thinning, regardless history of ON. RNFL thinning could be used as a possible MS outcome measure and as surrogate endpoint for MS disability. Furthermore, RNFL can provide complementary information in relation to MS patients' vision.

Keywords: Ocular coherence tomography; Optic neuritis; Retinal nerve fiber layer; Multiple Sclerosis

Abbreviations: OCT: Optical Coherence Tomography; MS: Multiple Sclerosis; ON: Optic Neuritis; MRI: Magnetic Resonance Imaging; MSON: Multiple Sclerosis Optic Neuritis; MSNON: Multiple Sclerosis-Non Optic Neuritis; RNFL: Retinal Nerve Fiber Layer; MV: Macular Volume; BCVA: Best-corrected Visual Acuity; LCVA: Low-contrast Visual Acuity; VA: Visual Acuity; CS: Contrast Sensitivity; CI: Confidence Interval; OR: Odds Ratio

\section{Introduction}

Multiple Sclerosis (MS) is an autoimmune disease of the Central Nervous System (CNS) characterized by chronic inflammation and neurodegeneration. Axonal degeneration, although more profound in the later stages of the disease, may be present even in the early stages of the disease course. In addition, Optic Neuritis (ON) is an early feature of MS and almost $70-80 \%$ of patients develop ON during the course of their disease. Optical Coherence Tomography (OCT) is a relatively new imaging technique which serves as a promising and sensitive tool for measuring the thickness of the Retinal Nerve Fiber Layer (RNFL) and with a cost of approximately 10 to $15 \%$ less than that of Magnetic Regional Imaging (MRI) [1]. Several recent studies have denoted that OCT can detect RNFL thinning, regardless of ON clinical history, probably due to axon damage in the patients retinas, suggesting that this may be an effective biomarker. 
In addition, OCT is a non-invasive technique which provides a reliable way for an in vivo optical biopsy of accessible tissues like the retina $[2,3]$. OCT has evolved into an interesting and highly accurate method for the imaging of neurodegeneration and axonal loss in MS within the last ten years. The RNFL consists mainly of retinal ganglion cell axons, which are unmyelinated and thus measures axonal loss [4]. A number of studies have also reported RNFL thinning in clinically unaffected eyes with MS when compared to healthy ones. The degree of reduction of the RNFL thickness following ON is consistent with the outcome of the quantitative analyses of visual dysfunction [5-8] as well as with the global measures of disability in MS as suggested in other studies [1,9]. A study performed by OCT supported that the detection of RNFL thickness loss is not confounded by any concurrent myelin loss in patients with a history of unilateral ON compared to the fellow eye [6]. Additional studies show that MS patients display RNFL thinning both with and without a history of ON $[10,11]$. In the present study we conducted a search of medical literature on all studies using OCT to screen patients with MS. Finally, RNFL thinning is discussed as a possible MS outcome measure, especially as a biomarker for MS disability $[12,13]$.

\section{Materials and Methods}

\section{Search strategy and selection criteria}

We searched Pub Med/Medline database, from 2006 to the end of March 2019, using the generic terms Optic Neuritis, Ocular Coherence Tomography, Retinal Nerve Fiber, and Multiple Sclerosis. All the studies identified in this systematic review were using OCT technology based on the stratus OCT to screen patients with MS. The included publications were written in
English language and RNFL, BCVA and MV measurements could be obtained from the eligible studies. Publications in languages other than English were excluded. In addition, experimental research in animal models was also excluded as well as review articles and case reports. Abstracts and full-texts included in the analysis were screened by titled and abstract by two of the authors independently (E.M. and S-H.P.) using the abovementioned inclusion and exclusion criteria. From each article we recorded the following data: name of the first author, title of the study, year and PMID of publication, number, sex, mean age of cases and controls in each study. Cochrane Collaborations Review Manager 5.3 was used for the analysis of the obtained data of each study.

Since the present study was based on data retrieved from the literature did not require ethical approval from our authorities.

\section{Results}

A total of 3265 studies matched the inclusion criteria (Figure 1) and considered for the study. A total of 1497 articles were excluded according to selection criteria. From the remaining 1768 articles, we excluded 47 articles of experimental research and 1608 articles as reviews or case reports. Finally, of the 113 articles included in the meta-analysis, 48 were further excluded as their data presentation lacked the necessary details for inclusion in the study. At the end, 65 articles were eligible for systematic review of OCT parameters in MS patients. Flow of information through the different phases of the literature search is shown in figure 1. The mean difference, which enables the comparison of the RNFL thickness among groups of interest, was chosen as an effect measure.

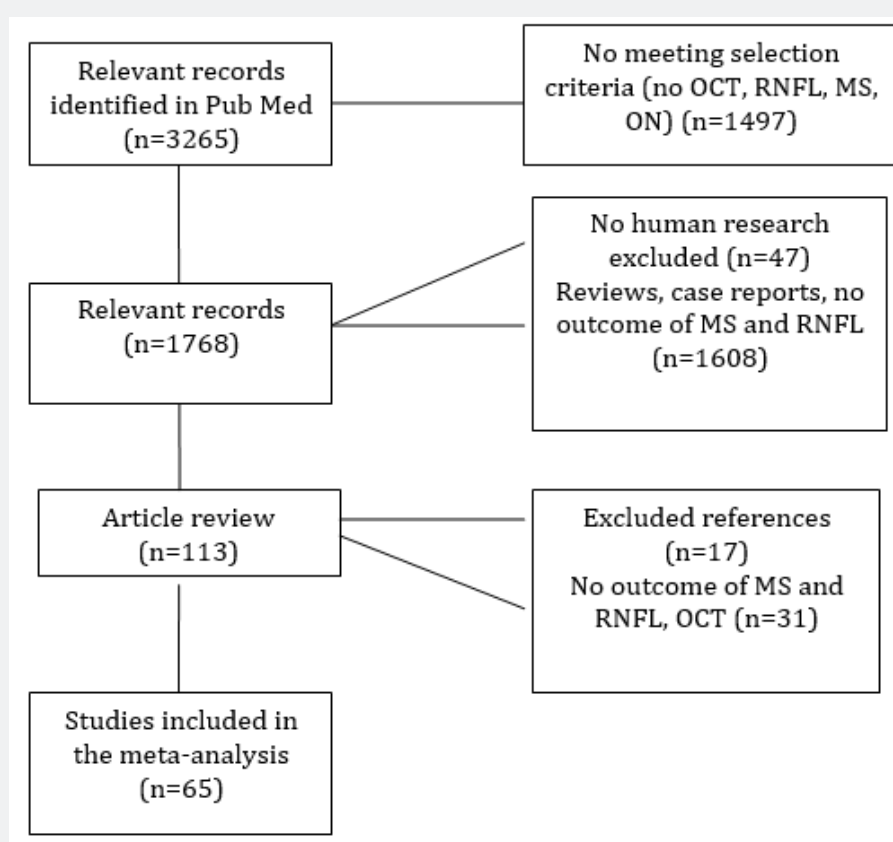

Figure 1: Flow of information through the different phases of the literature search. 
A total of 4 groups of studies were included in the systematic review: 1) Multiple Sclerosis Optic Neuritis (MSON) affected eyes compared to healthy controls (Figure 2), multiple sclerosisnon optic neuritis (MSNON) affected eyes compared to healthy controls (Figure 3), Macular Volume (MV) of patients with MS compared to healthy controls (Figure 4), and 4) Best-Corrected Visual Acuity (BCVA) of patients with MS compared to healthy controls (Figure 5).

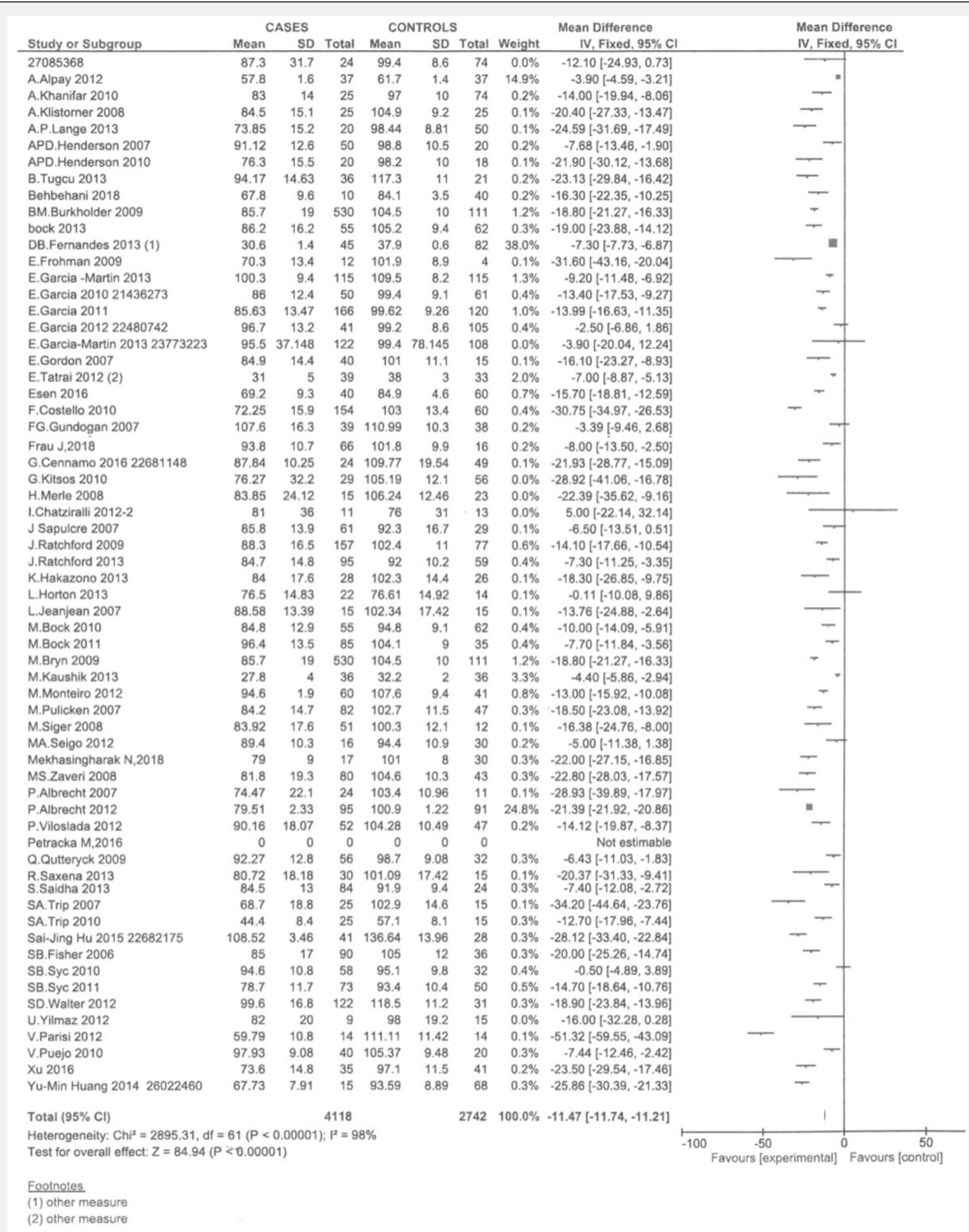

Figure 2: Meta-analysis of OCT studies in patients with MSON and forest plot of mean difference in RNFL thickness between MSON eyes and controls; Mean difference in RNFL thickness between ON eyes and controls is provided in $\mu \mathrm{m}$. OCT: optical coherence tomography, MSON: multiple sclerosis optic neuritis, RNFL: retinal nerve fiber layer. 


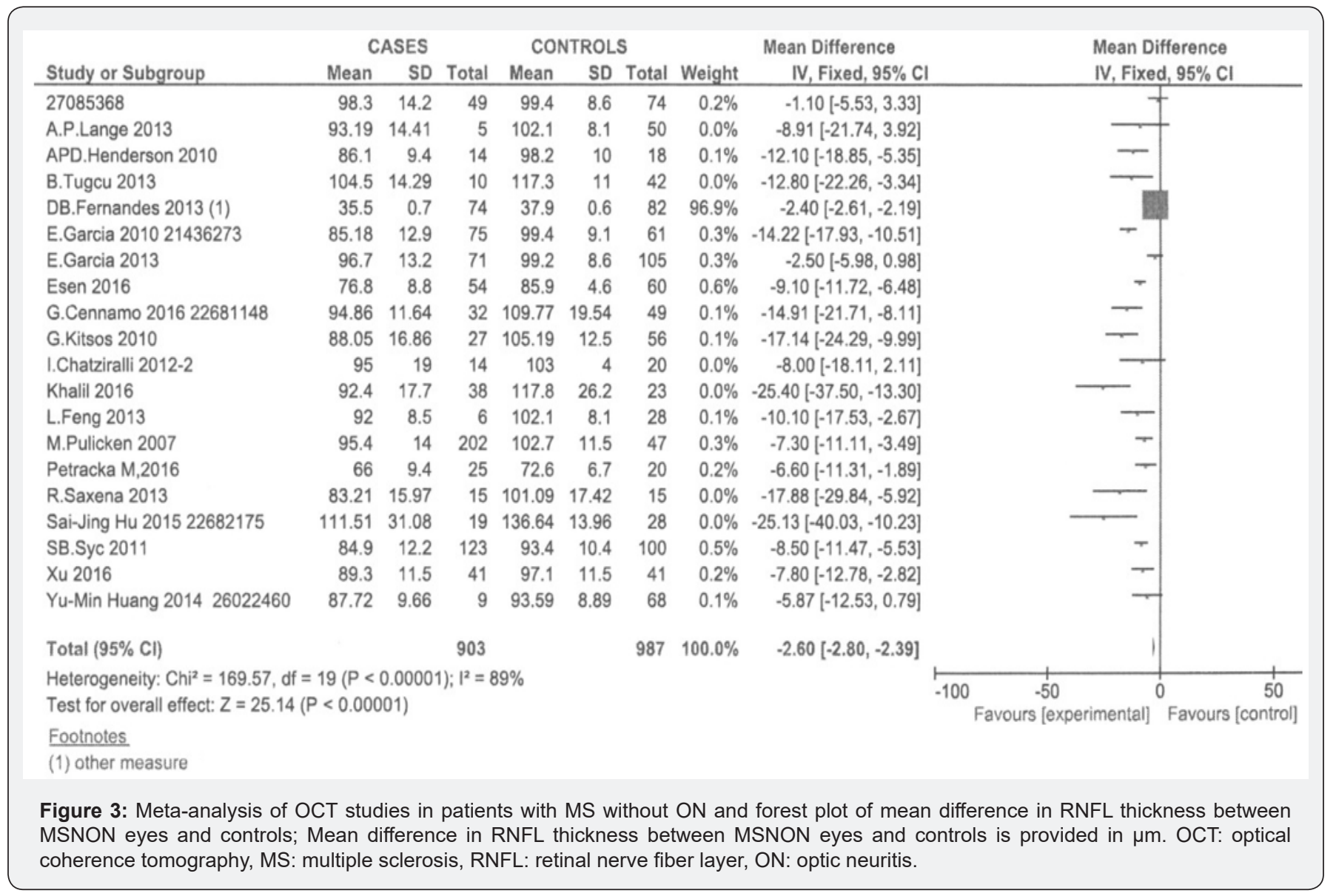

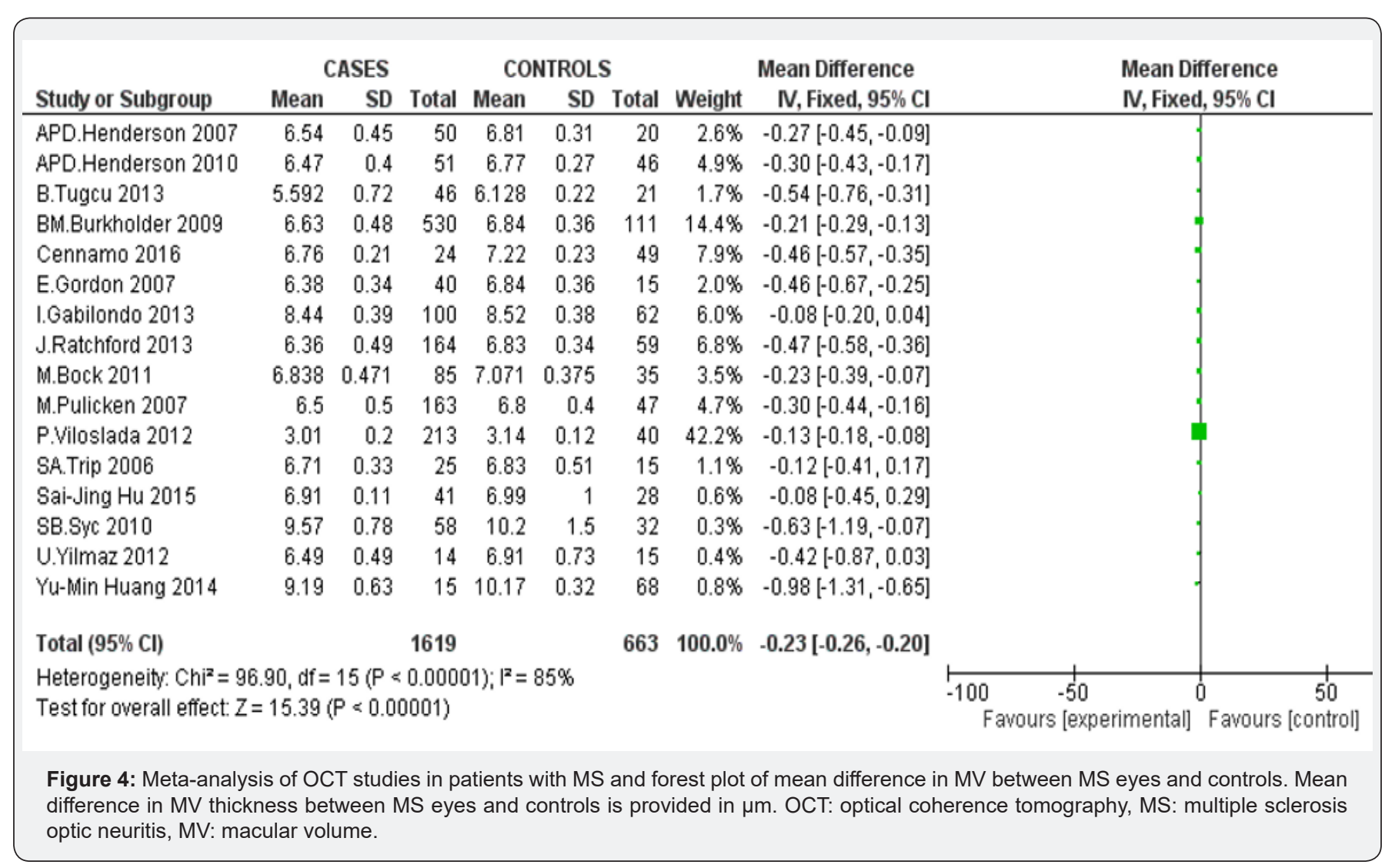




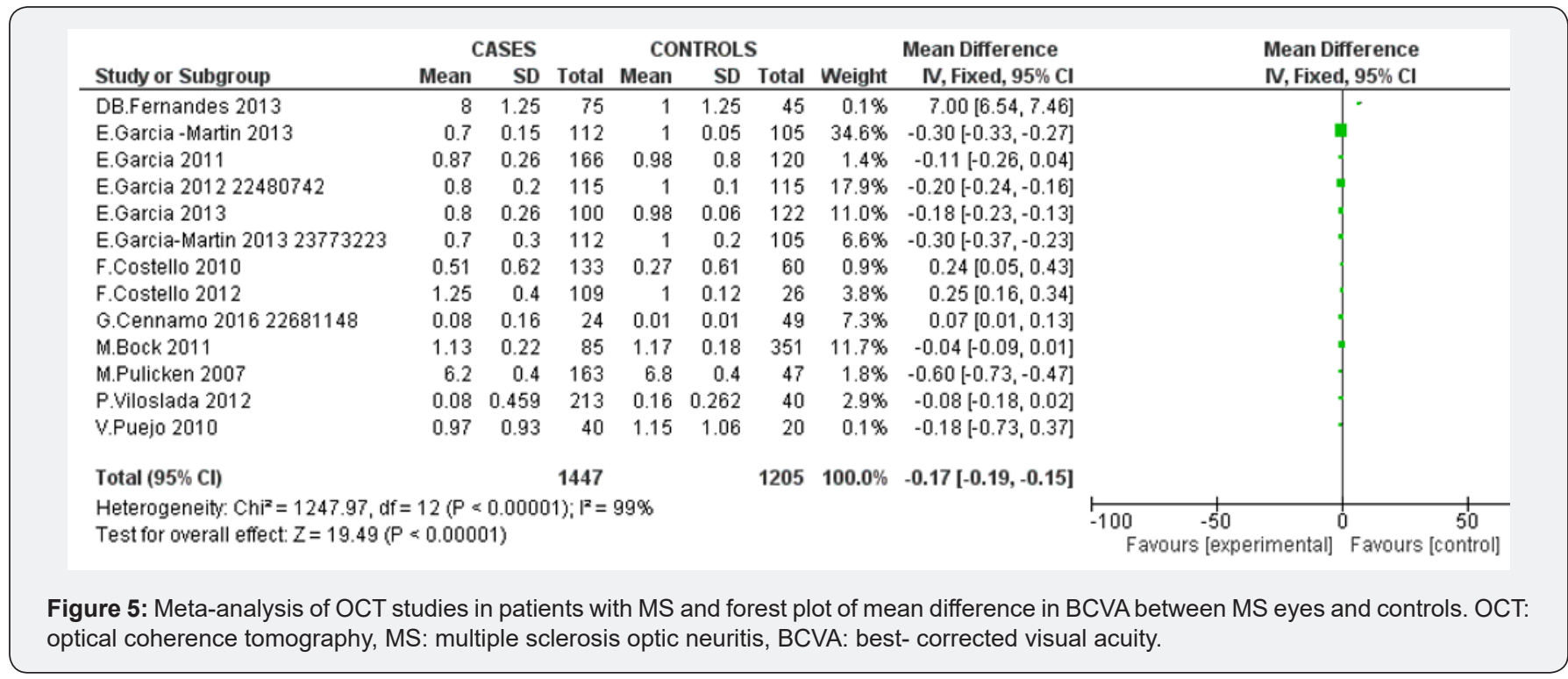

RNFL in MSON and MSNON, MV and BCVA from the 65 eligible studies analyzed by Cochrane Collaborations Review Manager 5.3 program were as follows

\section{RNFL MSON}

The meta-analysis results of the 65 eligible studies which compared eyes of MS patients affected by ON $(n=4118)$ with eyes of healthy controls $(n=2742)$ gave an estimated average RNFL thinning following MSON of $-11.47 \mu \mathrm{m}$ [95\% CI -11.74 to -11.21, $\mathrm{n}=6860, \mathrm{p}<0.00001$ ] (Figure 2).

\section{RNFL MSNON}

We singled out of 65 eligible studies for the meta-analysis 20 studies which compared the RNFL thickness of MSNON eyes with healthy controls eyes. The estimated RNFL loss in MSNON eyes $(n=903)$ compared with controls ones $(n=987)$ was lower $(-2.60)$ than the one following MSON $(-11.47)$, but the 95\% CI was narrower $-2.60[-2.80$ to $-2.39, \mathrm{n}=1890, \mathrm{p}<0.00001]$ (Figure 3).

\section{MV}

We examined out of 65 studies eligible for the meta-analysis 16 studies comparing MV in eyes of MS patients with that of healthy controls. The summary data of 2282 investigated eyes (1619 with MS vs. 663 controls) are shown in Figure 4. The MV thickness among MS eyes and controls was within an estimated average of $-0.23 \mu \mathrm{m}$ [95\% CI -0.26 to $-0.20, \mathrm{n}=2282, \mathrm{p}<0.00001]$ (Figure 4).

\section{BCVA}

We examined out of 65 eligible studies for the meta-analysis 13 studies comparing BCVA of MS patients' eyes with that of healthy controls. The summary data of 2652 investigated eyes (1447 with MS vs. 1205 controls) are shown in Figure 5. The BCVA among MS patients' eyes and controls was within an estimated average of -0.17 [95\% CI -0.19 to $-0.15, n=2652$, $\mathrm{p}<0.00001$ ] (Figure 5).

\section{Discussion}

In the present study retinal measures for healthy controls were greater than those of MS patients with or without ON across all measured parameters. OCT is used to detect axonal loss in MS patients, even in those featuring subclinical defects. The visual acuity measurements were strongly in consistent with the RNFL thickness values, denoting that RNFL can provide complementary, not overlapping, information in relation to MS patients' vision, thus highlighting the significance of examining vision in MS patients [7]. It is possible to detect any occurring deterioration of the optic nerve function even in MS patients exhibiting no prior symptoms of visual damage [14-16]. The RNFL reduction was also correlated with the visual field in MSON and MSNON patients, while in another study such correlation was observed only in MSON eyes [15]. A significant reduction in RNFL thickness was observed in MSON eyes which is consistent in all studies performed using separate methods of retinal fiber assessment [17]. The values of RNFL thickness and visual function were even more reduced in recurrent ON eyes, thus OCT was proposed as a biomarker for evaluation of the vision of MS patients $[18,19]$. After evaluating their findings, the authors concluded that repetitive inflammatory incidents could consequently lead to visual impairment. Retinal thinning was observed to be greater in patients' eyes with prior history of ON than in those of controls [20].

Saxena et al. [21] evaluated that RNFL thinning in ON cases was linked to severe visual field deficiencies, while in MS cases was more associated with contrast sensitivity and stereo acuity. Additionally, eyes with an ON history had a significantly reduced RNFL thickness compared with that group of non-ON history [22]. RNFL reduction may manifest in both relapsing-remitting 
and secondary progressive MS patients [23]. Moreover, a steady reduction in average RNFL thickness in MSON eyes is advancing over time [24]. The RNFL reduction could be explained by secondary axonal degeneration linked to focal lesions affecting the visual pathways or by diffuse advancing axonal degeneration attributed to a compartmentalized progressive inflammation in the brain [24]. A subclinical RNFL thinning is likely to manifest even in MS patients without clinical ON history [25-28]. In many studies, the difference in RNFL thickness between MSON eyes and MSNON fellow eyes was reported statistically insignificant [29-40]. These findings highlight the significance of thoroughly investigating all evidence in MSNON in order to limit the risk of overlooking a more subtle RNFL loss due to an inferred retrograde trans-synaptic degeneration caused by the damaged anterior visual pathways in MSNON [41-59].

In addition, MV values of MS patients' eyes evaluated within a 12-month period shown a decreasing trend in all patients. In these studies, MV reduction, both in MS patients and healthy controls, was similarly proportionate [59-61]. A Fast-Macular Thickness scanning was used in order to estimate MV. The authors suggested that MV assessment was more sensitive means of detecting age-related retinal alterations because the macula contains a proportionally higher number of ganglion cells in comparison to RNFL. Furthermore, MV reduction was observed on eyes of MS patients both with and without history of ON.

Moreover, a number of studies [62-65] reported correlation of the temporal sector with the visual acuity, in comparison to the correlations of the superior, inferior and nasal quadrant which detected no significant differences. In addition, MS patients displayed impaired Low-Contrast Visual Acuity (LCVA) in comparison to healthy controls [65]. According to that study, from the early stages of the disease up to the advanced ones, MS patients demonstrated impairment in LCVA as well as in color vision with gradually deterioration with progression of time.

\section{Conclusion}

OCT is an extensively recognized tool which is used to measure RNFL and MV thicknesses in MS patients. These measurements could provide valuable information regarding axonal loss and neuronal cell layer thinning regardless ON. Moreover, VA measurements were found to be strongly in consistence with the RNFL thickness values, denoting that RNFL can provide complementary but not overlapping information in relation to MS patients' vision. Following axonal loss and axonal injury by means of OCT might be a useful and reliable measure in clinical studies evaluating neuroprotective therapies for MS.

\section{Acknowledgment}

The financial support of HELANI (Hellenic Academy of Neuroimmunology) to Sygkliti-Henrietta Pelidou is gratefully acknowledged. "authors contributed equally.

\section{References}

1. Gordon-Lipkin E, Chodkwski B, Reich DS, Smith SA, Pulicken M, et al. (2007) Retinal nerve fibre layer is associated with brain atrophy in multiple sclerosis. Neurology 69(16): 1603-1609.

2. Huang D, Swanson EA, Lin CP, Schuman JS, Stinson WG, et al. (1991) Optical coherence tomography. Science 254(5035): 1178-1181.

3. Petzold A, Johannes F de Boer, Schippling S, Vermersch P, Kardon R, et al. (2010) Optical coherence tomography in multiple sclerosis: a systematic review and meta-analysis. Lancet Neurology 9(9): 921-932.

4. Henderson APD, Trip SA, Schlottmann PG, Altmann DR, Garway-Heath DF, et al. (2010) A preliminary longitudinal study of the retinal nerve fibre layer in progressive multiple sclerosis. J Neurol 257(7): 10831091.

5. Cheng H, Laron M, Schiffman JS, Tang RA, Frishman LJ (2007) The relationship between visual field and retinal nerve fiber layer measurements in patients with multiple sclerosis. Invest Ophthalmol Vis Sci 48(12): 5798-5805.

6. Henderson APD, Trip SA, Schlottmann PG, Altmann DR, Garway-Heath DF, et al. (2008) An investigation of the retinal nerve fibre layer in progressive multiple sclerosis using optical coherence tomography. Brain 131(1): 277-287.

7. Pulicken M, Gordon-Lipkin E, Balcer LJ, Frohman E, Cutter G (2007) Optical coherence tomography and disease subtype in multiple sclerosis. Neurology 69(22): 2085-2092.

8. Trip SA, Schlottmann PG, Jones SJ, Li WY, Garway-Heath DF, et al. (2006) Optic nerve atrophy and retinal nerve fibre layer thinning following optic neuritis: Evidence that axonal loss is a substrate of MRI-detected atrophy. NeuroImage 31(1): 286-293.

9. Toledo J, Sepulcre J, Salinas-Alaman A, García-Layana A, MurieFernandez M, et al. (2008) Retinal nerve fibre layer atrophy is associated with physical and cognitive disability in multiple sclerosis. Mult Scler 14(7): 906-912.

10. Albrecht P, Froehlich R, Hartung HP, Kieseier BC, Methner A (2007) Optical coherence tomography measures axonal loss in multiple sclerosis independently of optic neuritis. J Neurol 254(11): 1595-1596.

11. Saidha S, Syc SB, Durbin MK, Eckstein C, Oakley JD, et al. (2011) Visual dysfunction in multiple sclerosis correlates better with optical coherence tomography derived estimates of macular ganglion cell layer thickness than peripapillary retinal nerve fibre layer thickness. Mult Scler 17(12): 1449-1463.

12. Walter SD, Ishikawa H, Galetta KM, Sakai RE, Feller DJ, et al. (2012) Ganglion cell loss in relation to visual disability in multiple sclerosis. Ophthalmology 119(6): 1250-1257.

13.Zaveri MS, Conger A, Salter A, Frohman TC, Galetta SL, et al. (2008) Retinal imaging by laser polarimetry and optical coherence tomography evidence of axonal degeneration in multiple sclerosis. Arch Neurol 65(7): 924-928.

14. Alpay A, Guney T, Unal A, Ugurbas SH (2012) Comparison of retinal nerve fibre layer thickness with visual evoked potential and visual field in patients with multiple sclerosis. Clin Exp Ophthalmol 40(1): 25-31.

15. Kitsos G, Detorakis ET, Papakonstantinou S, Kyritsis AP, Pelidou SH (2011) Perimetric and peri-papillary nerve fibre layer thickness findings in multiple sclerosis. Eur J Neurol 18(5): 719-725.

16. Pueyo V, Ara JR, Almarcegui C, Martin J, Güerri N, et al. (2010) Subclinical atrophy of the retinal nerve fibre layer in multiple sclerosis. Acta Ophthalmol 88(7): 748-752.

17. Parisi V, Manni G, Spadaro M, Colacino G, Restuccia R, et al. (1999) Correlation between morphological and functional retinal impairment 


\section{Open Access Journal of Neurology \& Neurosurgery}

in multiple sclerosis patients. Invest Ophthalmol Vis Sci 40(11): 25202527.

18. Trip SA, Schlottmann PG, Jones SJ, Altmann DR, Garway-Heath DF, et al. (2005) Retinal nerve fibre layer axonal loss and visual dysfunction in optic neuritis. Ann Neurol 58(3): 383-391.

19. Gundogan FC, Demirkaya S, Sobaci G (2007) Is optical coherence tomography really a new biomarker candidate in multiple sclerosis? A structural and functional evaluation. Invest Ophthalmol Vis Sci 48(12): 5773-5781.

20. Yilmaz A, Gócóyener K, Erin DM, Yazar Z, Gürkaş E, et al. (2012) Reduced retinal nerve fibre layer thickness and macular volume in paediatric multiple sclerosis. J Child Neurol 27(12): 1517-1523.

21. Saxena R, Bandyopadhyay G, Singh D, Singh S, Sharma P, et al. (2013) Evaluation of changes in retinal nerve fibre layer thickness and visual functions in cases of optic neuritis and multiple sclerosis. Indian J Ophthalmol 61(10): 562-566.

22. Fisher JB, Jacobs DA, Markowitz CE, Galetta SL, Volpe NJ, et al. (2006) Relation of visual function to retinal nerve fibre layer thickness in multiple sclerosis. Ophthalmology 113(2): 324-332.

23. Tugcu B, Soysal A, Kilic M, Yuksel B, Kale N, et al. (2013) Assessment of structural and functional visual outcomes in relapsing remitting multiple sclerosis with visual evoked potentials and optical coherence tomography. J Neurol Sci 335(1-2): 182-185.

24. Chatziralli IP, Moschos MM, Brouzas D, Kopsidas K, Ladas ID (2012) Evaluation of retinal nerve fibre layer thickness and visual evoked potentials in optic neuritis associated with multiple sclerosis. Clin Exp Optom 95(2): 223-228.

25. Costello F, Hodge W, Pan YI, Eggenberger E, Coupland S, et al. (2008) Tracking retinal nerve fibre layer loss after optic neuritis: a prospective study using optical coherence tomography. Mult Scler 14(7): 893-905.

26. Villoslada P, Cuneo A, Gelfand J, Hauser SL, Green A (2012) Color vision is strongly associated with retinal thinning in multiple sclerosis. Mult Scler 18(7): 991-999.

27. Syc SB, Warner CV, Hiremath GS, Farrell SK, Ratchford JN, et al. (2010) Reproducibility of high-resolution optical coherence tomography in multiple sclerosis. Mult Scler 16(7): 829-839.

28. Siger M, Dziegielewski K, Jasek L, Bieniek M, Nicpan A, et al. (2008) Optical coherence tomography in multiple sclerosis: thickness of the retinal nerve fibre layer as a potential measure of axonal loss and brain atrophy. J Neurol 255(10): 1555-1560.

29. Ratchford JN, Quigg ME, Conger A, Frohman T, Frohman E, et al. (2009) Optical coherence tomography helps differentiate neuromyelitis optica and MS optic neuropathies. Neurology 73(4): 302-308.

30. Behbehani R, Al-Hassan AA, Al-Salahat A, Sriraman D, Oakley JD, et al. (2017) Optical coherence tomography segmentation analysis in relapsing remitting versus progressive multiple sclerosis. PLoS One 12(2): e0172120.

31. Puthenparampil M, Federle L, Poggiali D, Miante S, Signori A, et al. (2017) Trans-synaptic degeneration in the optic pathway. A study in clinically isolated syndrome and early relapsing-remitting multiple sclerosis with or without optic neuritis. PLoS One 12(8): e0183957.

32. Huang-Link YM, Fredrikson M, Link H (2015) Benign Multiple Sclerosis is Associated with Reduced Thinning of the Retinal Nerve Fiber and Ganglion Cell Layers in Non-Optic-Neuritis Eyes. J Clin Neurol 11(3): 241-247.

33. Laible M, Jarius S, Mackensen F, Schmidt-Bacher A, Platten M, et al. (2016) Adding papillomacular bundle measurements to standard optical coherence tomography does not increase sensitivity to detect prior optic neuritis in patients with multiple sclerosis. PLoS One 11(5): e0155322.

34. Hu SJ, You YA, Zhang Y (2015) A study of retinal parameters measured by optical coherence tomography in patients with multiple sclerosis. Int J Ophthalmol 8(6): 1211-1214.

35. Esen E, Sizmaz S, Balal M, Yar K, Demirkiran M, et al. (2016) Evaluation of the innermost retinal layers and visual evoked potentials in patients with multiple sclerosis. Curr Eye Res 41(10): 1353-1358.

36. Petracca M, Cordano C, Cellerino M, Button J, Krieger S, et al. (2016) Retinal degeneration in primary-progressive multiple sclerosis: a role for cortical lesions? Mult Scler 23(1): 43-50.

37. Khalil DH, Said MM, Abdelhakim MASE, Labeeb DM (2017) OCT and visual field changes as useful markers for follow-up of axonal loss in multiple sclerosis in Egyptian patients. Ocul Immunol Inflamm 25(3): 315-322.

38. Frau J, Fenu G, Signori A, Coghe G, Lorefice L, et al. (2018) A crosssectional and longitudinal study evaluating brain volumes, RNFL and cognitive functions in MS patients and healthy controls. BMC Neurol 18(1): 67.

39. Xu LT, Bermel RA, Nowacki AS, Kaiser PK (2016) Optical coherence tomography for the detection of remote optic neuritis in multiple sclerosis. J Neuroimaging 26(3): 283-288.

40. Mekhasingharak N, Laowanapiban P, Siritho S, Satukijchai C, Prayoonwiwat N, et al. (2018) Optical coherence tomography in central nervous system demyelinating diseases related optic neuritis. Int J Ophthalmol 11(10): 1649-1656.

41. Tatrai E, Sim M, Iljicsov A, Németh J, Debuc DC, et al. (2012) In vivo evaluation of retinal neuro-degeneration in patients with multiple sclerosis. PLoS One 7(1): e30922.

42. Outteryck O, Zephir H, Defoort S, Bouyon M, Debruyne P, et al. (2009) Optical coherence tomography in clinically isolated syndrome: no evidence of subclinical retinal axonal loss. Arch Neurol 66(11): 13731377.

43. Sepulcre J, Murie-Fernandez M, Salinas-Alaman A, García-Layana A, Bejarano B, et al. (2007) Diagnostic accuracy of retinal abnormalities in predicting disease activity in MS. Neurology 68(18): 1488-1494.

44. Klistorner A, Arvind H, Nguyen T, Garrick R, Paine M, et al. (2008) Axonal loss and myelin in early $\mathrm{ON}$ loss in postacute optic neuritis. Ann Neurol 64(3): 325-331.

45. Monteiro ML, Fernandes DB, Apostolos-Pereira SL, Callegaro D (2012) Quantification of retinal neural loss in patients with neuromyelitis optica and multiple sclerosis with or without optic neuritis using Fourier-domain optical coherence tomography. Invest Ophthalmol Vis Sci 53(7): 3959-3966

46. Frohman EM, Dwyer MG, Frohman T, Cox JL, Salter A, et al. (2009) Relationship of optic nerve and brain conventional and nonconventional MRI measures and retinal nerve fibre layer thickness, as assessed by OCT and GDx: a pilot study. J Neurol Sci 282(1-2): 96-105.

47. Hakazono K, Raza AS, Oyamad MK, Hood DC, Monteiro ML (2013) Pattern electroretinogram in neuromyelitis optica and multiple sclerosis with or without optic neuritis and its correlation with FDOCT and perimetry. Doc Ophthalmol 127(3): 201-215.

48. Syc SB, Saidha S, Newsome SD, Ratchford JN, Levy M, et al. (2012) Optical coherence tomography segmentation reveals ganglion cell layer pathology after optic neuritis. Brain 135(2): 521-533.

49. SA Trip, PG Schlottmann, SJ Jones, Kallis C, Altmann DR, et al. (2010) Scanning laser polarimetry quantification of retinal nerve fibre layer thinning following optic neuritis. J Neuroopththalmol 30(3): 235-242. 


\section{Open Access Journal of Neurology \& Neurosurgery}

50. Albrecht P, Ringelstein M, Müller AK, Keser N, Dietlein T, et al. (2012) Degeneration of retinal layers in multiple sclerosis subtypes quantified by optical coherence tomography. Mult Scler 18(10): 1422-1429.

51. Kaushik M, Wang CY, Barnett MH, Garrick R, Parratt J, et al. (2013) Inner nuclear layer thickening is inversely proportional to retinal ganglion cell loss in optic neuritis. PLos One 8(10): e78341.

52. Lange AP, Sadjadi R, Zhu F, Alkabie S, Costello F, et al. (2013) Spectraldomain optical coherence tomography of retinal nerve fibre layer thickness in NMO patients. J Neuroophthalmol 33(3): 213-219.

53. Khanifar AA, Parlitsis GJ, Ehrlich JR, Aaker GD, DAmico DJ, et al. (2010) Retinal nerve fibre layer evaluation in multiple sclerosis with spectra domain optical coherence tomography. Clin Ophthalmol 20(4): 10071013.

54. Seigo MA, Sotirchos ES, Newsome S, Babiarz A, Eckstein C, et al. (2012) In vivo assessment of retinal neuronal layers in multiple sclerosis with manual and automated optical coherence tomography segmentation techniques. J Neurol 259(10): 2119-2130.

55. Garcia-Martin E, Herrero R, Bambo MP, Ara JR, Martin J, et al. (2015) Artificial neural network techniques to improve the ability of optical coherence tomography to detect optic neuritis. Semin Ophthalmol 30(1): 11-19.

56. Horton L, Conger A, Conger D, Remington G, Frohman T, et al. (2013) Effect of 4-aminopyridine on vision in multiple sclerosis patients with optic neuropathy. Neurology 80(20): 1862-1866.

57. Trip SA, Schlottmann PG, Jones SJ, Li WY, Garway-Heath DF, et al. (2007) Optic nerve magnetization transfer imaging and measures of axonal loss and demyelination in optic neuritis. Mult Scler 13(7): 875879

58. Jeanjean L, Castelnovo G, Carlander B, Villain M, Mura F, et al. (2008)
Retinal atrophy using optical coherence tomography (OCT) in 15 patients with multiple sclerosis and comparison with healthy subjects. Rev Neurol (Paris) 164(11): 927-934.

59. Merle H, Olindo S, Donnio A, Richer R, Smadja D, et al. (2008) Retinal peripapillary nerve fibre layer thickness in neuromyelitis optica. Invest Ophthalmol Vis Sci 49(10): 4412-4417.

60. Burkholder BM, Osborne B, Loguidice MJ, Bisker E, Frohman TC, et al (2009) Macular volume determined by optical coherence tomography as a measure of neuronal loss in multiple sclerosis. Arch Neurol 66(11): 1366-1372.

61. Ratchford JN, Saidha S, Sotirchos ES, Oh JA, Seigo MA, et al. (2013) Active MS is associated with accelerated retinal ganglion cell/inner plexiform layer thinning. Neurology 80(1): 47-54.

62. Garcia-Martin E, Pablo LE, Herrero R, Satue M, Polo V, et al. (2012) Diagnostic ability of a linear discriminant function for spectral-domain optical coherence tomography in patients with multiple sclerosis. Ophthalmology 119(8): 1705-1711.

63. Garcia-Martin E, Pueyo V, Pinilla I, Ara JR, Martin J, et al. (2011) Fourier-domain OCT in multiple sclerosis patients: reproducibility and ability to detect retinal nerve fibre layer atrophy. Invest Ophthalmol Vis Sci 52(7): 4124-4131.

64. Bock M, Brandt AU, Kuchenbecker J, Dörr J, Pfueller CF, et al. (2012) Impairment of contrast visual acuity as a functional correlate of retinal nerve fibre layer thinning and total macular volume reduction in multiple sclerosis. Br J Ophthalmol 96(1): 62-67.

65. Bock M, Brandt AU, Dörr J, Pfueller CF, Ohlraun S, et al. (2010) Time domain and spectral domain optical coherence tomography in multiple sclerosis: a comparative cross-sectional study. Mult Scler 16(7): 893896.

\section{Your next submission with Juniper Publishers will reach you the below assets}

- Quality Editorial service

- Swift Peer Review

- Reprints availability

- E-prints Service

- Manuscript Podcast for convenient understanding

- Global attainment for your research

- Manuscript accessibility in different formats

( Pdf, E-pub, Full Text, Audio)

- Unceasing customer service

Track the below URL for one-step submission

https://juniperpublishers.com/online-submission.php 